\title{
Analysis on factors influencing Ningxia Guyuan people's sports consciousness and behavior
}

\author{
Peibang Zhu \\ Physical Education Institute, Ningxia Normal University, Guyuan Ningxia, 756000, China
}

Keywords: Guyuan City, Social class, Sport consciousness and behavior, Factor.

\begin{abstract}
In the period of society's rapid transformation, with the improvement of people's living standard and attention to health in Guyuan City, it is obvious that people's fitness consciousness and behaviors have changed but there still exist shortcomings. Under the macro background of economic rapid progress and the stagnation of social development, this article has analyzed the influence on the consciousness and behaviors of people from different social classes when they participate in physical exercise, proposed to energetically change social resource allocation and social resource equality so as to provide good condition and environment for people's physical exercise at different social classes.
\end{abstract}

\section{Introduction}

Human beings' comprehensive physical depends on the engine body's growth and development level to a large degree, and also depends on the effect of physical exercise. Except for daily diet and rest, physical exercise plays an extremely important role in improving human's comprehensive physical quality. Consciousness leads behaviors and determines human beings' action. Thus, continuously improvement of people's sport consciousness is very important. It can further promote physical exercise to be routine and life-oriented in China and continuously improve people's physical condition. This article has conducted comprehensive and in-depth analysis on factors influencing people's sport consciousness and behaviors, and also proposed several humble opinions for reference.

\section{Introduction of sport consciousness and behavior}

Sport consciousness also refers to sport concept which is a philosophy of spirit and consciousness, as well as the ideological outcome after human beings' long-term sport practice and rational thinking[1-2]. Generally speaking, sport consciousness is a kind of understanding with systematisms, consciousness and rationalization and a prospect and pursuit of human beings. But sports behavior refers to a series of sport exercise under the guidance of sport consciousness.

\section{Sport value}

Sport value generally refers to the relationship between the effect of sports and human beings. From a comprehensive perspective, sport value mainly include extrinsic value and intrinsic value:

Extrinsic value of sports mainly includes: extrinsic value of human physical agility; extrinsic value of sports skills; extrinsic value of sports knowledge; and extrinsic value of sports happiness [3].

Intrinsic value mainly includes: Intrinsic value of human physical agility; intrinsic value of sports skills; intrinsic value of sports knowledge; and intrinsic value of sports happiness.

\section{Property of sport consciousness}

Property of sport value mainly include: (1)Human nature and sociality(2)Subjectivity and objectivity

(3) Reality and necessity (4)Expansion and limitation[4]. 


\section{Major factors influencing sport consciousness and behaviors in different social classes of Guyuan City}

Table 1. Economic structure of Guyuan City in 2015

\begin{tabular}{|c|c|c|c|c|}
\hline & The primary industry & \multicolumn{2}{|c|}{$\begin{array}{c}\text { The secondary } \\
\text { industry }(\%)\end{array}$} & \multicolumn{2}{c|}{ The tertiary industry } & Total \\
\hline GDP (100 million) & $45.23 \quad 20.8$ & $59.03 \quad 27.2$ & 112.7852 & 217.04 \\
\hline $\begin{array}{c}\text { Employment } \\
10 \text { thousand people }\end{array}$ & 111.4374 .4 & 38.34 & 25.6 & 149.77 \\
\hline
\end{tabular}

Table 2. Employment structure of Guyuan City in 2015

\begin{tabular}{|c|c|c|c|c|c|c|c|}
\hline & $\begin{array}{c}16-25 \\
\text { years' old }\end{array}$ & $\begin{array}{c}26-35 \\
\text { years' old }\end{array}$ & $\begin{array}{c}36-45 \text { years' } \\
\text { old }\end{array}$ & $\begin{array}{c}46-55 \text { years' } \\
\text { old }\end{array}$ & $\begin{array}{c}56-65 \text { years' } \\
\text { old }\end{array}$ & $\begin{array}{c}66 \text { years' old } \\
\text { above }\end{array}$ & Total (\%) \\
\hline $\begin{array}{c}\text { The primary } \\
\text { industry }\end{array}$ & 210 & 206 & 215 & 217 & 216 & 240 & 130477.9 \\
\hline $\begin{array}{c}\text { The } \\
\text { secondary } \\
\text { industry }\end{array}$ & 28 & 33 & 31 & 17 & 18 & 3 & 1307.8 \\
\hline $\begin{array}{c}\text { The tertiary } \\
\text { industry }\end{array}$ & 41 & 67 & 59 & 44 & 22 & 6 & 23914.3 \\
\hline
\end{tabular}

Table 3. Urbanization of Guyuan City in 2016

\begin{tabular}{|l|c|c|c|c|c|}
\hline & Yuanzhou district & Longde County & Pengyang County & Jingyuan County & Xiji County \\
\hline Urbanization (\%) & 48.3 & 31.6 & 30.9 & 28.1 & 23.8 \\
\hline
\end{tabular}

Table 4. Major sites for sports events in rural and urban communities of Guyuan City

\begin{tabular}{|c|c|c|c|c|c|}
\hline & $\begin{array}{c}\text { Around } \\
\text { famer houses }\end{array}$ & $\begin{array}{c}\text { Basketball court, fitness } \\
\text { equipment sites }\end{array}$ & $\begin{array}{c}\text { Around } \\
\text { communities and } \\
\text { squares }\end{array}$ & $\begin{array}{l}\text { Rural spacious } \\
\text { sites }\end{array}$ & $\begin{array}{l}\text { Charging fitness } \\
\text { sites }\end{array}$ \\
\hline Class 1 & 15 & 48 & 9 & 42 & \\
\hline Class 2 & 150 & 216 & 16 & 316 & \\
\hline Class 3 & 3 & 13 & 39 & 16 & 3 \\
\hline Class 4 & 7 & 7 & 5 & 15 & \\
\hline Class 5 & 6 & 12 & 14 & 17 & 1 \\
\hline Class 6 & & 10 & 30 & 6 & 9 \\
\hline Class 7 & 14 & 13 & 60 & 7 & 14 \\
\hline Totals (\%) & 19517.2 & $319 \quad 28.1$ & $\begin{array}{ll}173 & 15.3 \\
\end{array}$ & $419 \quad 37$ & $27 \quad 2.4$ \\
\hline
\end{tabular}

Notes: according to the major features of social economy of Guyuan City, social class is mainly divided into following types. Class 1: urban and rural unemployed or semi-employed class; class 2: rural laborer; class 3: industry service industry; class 4: contract worker; class 5: individually-owned business; class 6: officer class; class 7: professional technicians.

Table 5. Schedule of factors non-participated in physical exercise of different social classes ( $\mathrm{n}=540)$

\begin{tabular}{|l|c|c|c|c|c|c|c|c|c|c|}
\hline & $\begin{array}{c}\text { Reason } \\
1\end{array}$ & $\begin{array}{c}\text { Reason } \\
2\end{array}$ & $\begin{array}{c}\text { Reason } \\
3\end{array}$ & $\begin{array}{c}\text { Reason } \\
4\end{array}$ & $\begin{array}{c}\text { Reason } \\
5\end{array}$ & $\begin{array}{c}\text { Reason } \\
6\end{array}$ & $\begin{array}{c}\text { Reason } \\
7\end{array}$ & Reason 8 & Reason 9 & Total \\
\hline Class 1 & 4 & 3 & 1 & 2 & 1 & 1 & & 1 & 13 \\
\hline Class 2 & 91 & 88 & 124 & 76 & 59 & 29 & 2 & 8 & 2 & 479 \\
\hline Class 3 & 4 & 3 & 5 & 1 & 3 & 1 & & & 17 \\
\hline Class 4 & 2 & 2 & 2 & 1 & 1 & & & & 10 & 14 \\
\hline Class 5 & 2 & 5 & 3 & 1 & 1 & 1 & 1 & & 3 \\
\hline Class 6 & 1 & 1 & & & 1 & & & & & 4 \\
\hline Class 7 & 1 & 1 & & 1 & 1 & & & & & 4 \\
\hline
\end{tabular}

Notes: reasons of non-participation: 1. Not free; 2: Not interested; 3. Tired in labor work, no energy; 4: afraid of being jeered;5: have no sport skills; 6: no site or equipment; 7: sick, not suitable for exercise; 8: strong body, no need to take exercise; 9: poor economic condition.

Guyuan City is located in southern mountain areas of Ningxia, belonging to old revolutionary base areas, distant and poverty-stricken areas and ethnic minorities living areas; total area of 10540 square meters, population of 1.51 million; as well as the key clustered poverty relief by the central 
government. Social class structure is the core structure, and the symbolic indicator is the proportion of middle class. In current industry structure of Guyuan City, output of first industry takes up 20.8\% but the number of employees in the first industry takes up 81\%. Farmers' povery is caused by structural and institutional problem. 34.7\% of urbanization in 2016 also indicated the structural and institutional problem which has also limited Guyuan citizens' pattern of views and values, behaviors and attitude, etc. Main fields for physical exercise in rural and urban communities are basketball courts and fitness facility sites. But most people taking exercise choose rural spacious sections and open sites in urban communities or parks.

\section{Main factors influencing migrant farmers' sport consciousness and behavior}

We can find based on above materials and table 5 that reasons that most migrant farmers in Guyuan City would not like to participate in sports exercise are below: first, they are busy with work all day long and it is hard for them to squeeze time for exercise; secondly, lack of sports hobbies and insufficient attention to their own health in their deep-rooted concept; thirdly, extremely lack of free exercise sites and in single structure; fourthly, short of money. They think everything costs money and want to save money; fifthly, poor mastery of sports exercise techniques. The factor of lack of professional organization has little influence [5-6]. Thus we can see, to further improve the current status of Guyuan migrant farmers' physical exercise, Guyuan municipal government and related departments should strengthen urban community and rural sport construction under the precondition of paying more attention to nationwide physical exercise, attach importance to the cultivation of sport professional talents and add more free exercise sites. In addition, they should strengthen the sound system of social security for migrant farmers and effectively reduce their work pressure so as to provide more free time for physical exercise. Also, they should enhance poverty relief and keep improving migrant farmers' economic and life standard so as to provide effective economic guarantee for migrant farmers to take physical exercise.

\section{Main factors influencing Guyuan students' sport consciousness and behavior}

\section{Influence of traditional exam-oriented education}

Even quality teaching has been proposed for years in China but China education circle and all sectors of society have not attached enough importance and support to it. Enrollment rate and score are still the evaluation standards of school and faculties by the society. Thus, exam-oriented education and theoretical education are still the focus of Chinese education career. There are less investment in physical education but more investment in intellectual education, and particularly rural areas are extremely short of sport resources. Due to schools' blind pursuit of enrollment rate, college entrance examination, the powerful "baton"[7]" has imposed great pressure to students who have to suffer from pressure from the school and society but bear expectations from parents. They have to fight and compete with each other and work hard as not far as if tying a beam and pricking with an awl in ancient time, but many students burn the candle at both ends to study in an irregular daily routine so that their physical condition is getting bad. To pursue enrollment rate, many schools have downsized PE class and even other subject teachers have taken over PE classes directly so that students barely have time for physical exercise. They can do nothing but study and get themselves immersed in books all day long in a model of "three points one rout" (classroom, canteen, and dormitory). Even the enrollment rate has increased in such condition, students' physical condition and activity and awareness to participate in physical exercise have declined continuously.

Influence of sport course teaching

From realistic perspective, a lot of schools arrange very few PE courses and almost all PE teachers have followed the "three basic" teaching in traditional teaching mode (basic knowledge teaching, basic technique teaching and basic skill teaching), but directly ignored students' individual differences and arrange teaching contents far away from students' individual development demands. PE teachers usually focus more on sport technique teaching but fail to implement the guiding thinking of "centering on students' quality development". In addition, most teaching methods used by PE teachers are same and boring, which cannot satisfy students' individual demands and also reduce the interestingness of PE class. Meanwhile, PE teachers under emphasize students' creation and initiative 
during teaching process, which has prevented students developing innovative ability and limited students' personal development to a large degree.

Influence of school sport atmosphere

Psychologists found through researches that environment has great influence on human behaviors and have a decisive role to a certain degree. Thus students' activity in participating in physical exercise is influenced by school sport environment and atmosphere mainly including campus sport cultural construction degree, PE teachers' professional comprehensive quality and other teachers' understanding of PE and students' sport consciousness. But take a broad view, under the pressure of enrollment rate, except for annual sports meeting, students are almost under the study pressure. As schools pay little attention to sport atmosphere, students will naturally lose their activity in participating in physical exercise. For a long time, the only few exercise consciousness are exhausted in a vicious circle so as not to promote the development of social sport career after they step into the society.

\section{Main factors influencing Guyuan civil servants' sport consciousness and behavior}

China's civil servant mainly refer to staffs in the administrative system of the traditional Chinese government, the members of which were selected by a competitive examination. Even members of this social class are not as busy with myriad of state affairs every day and they can legally enjoy leisure time during official holidays. But due to their role as a public servant, they are exposed to national affairs and work for the country and people, so they must be extremely prudent and careful in high intensity and pressure. Even most of time they are busy with work so that they have few time taking physical exercise, which is the most principal factor causing poor sport consciousness of Guyuan civil servants.

\section{Main factors influencing Guyuan professional personnel's consciousness and behaviors}

Even with the continuous development of social economy, people's life standard has improved greatly. Education issues, quality problem, food safety problem, environment problem and bad life habits have resulted in the increasing disease occurrence. Thus, under such social background, professional personnel seem especially important. Medical workers are one of busiest who are under the responsibility and pressure of healing the wounded and rescuing the dying. Such as primary and middle school teachers who have countless homework and classes for preparation, and other professional personnel who suffer from life pressure, work pressure, and psychological pressure and other pressure. In addition to a lot of personal, they feel helpless even wanting to actively participate in physical exercise. Meanwhile, it is undeniable that lack of the focus on their health is another factor influencing sport consciousness behavior.

\section{Strategies of improving Guyuan people's attention of sport consciousness and behaviors}

\section{Migrant farmers}

The country, autonomous region, Guyuan municipal government and relevant department should coordinate with each other to strengthen fitness publicity, build more free fitness places, organize colorful sports activities and provide relevant services and management;

Continue the social security system perfection for migrant farmers in this city, reasonably arrange their working time so as to effectively reduce their work pressure and provide more time to participate in physical exercise.

Guyuan municipal government should pay attention to improve migrant farmers' economic living condition and mental and cultural guidance, promote the harmonious development of their material life and spiritual life.

\section{Student}

Break traditional education and teaching concept of exam-oriented education, focus more on students' PE education, and reasonably arrange PE course;

Appropriately strengthen the material investment in sport facilities and mental support, satisfy 
students' demands of physical exercise;

Try to establish good campus sport cultural environment and suitable social sports and cultural atmosphere.

\section{Professional personnel aspect}

Arrange time for physical exercise regularly and at fixed time, regularly organize team form physical exercise activities (such as sports friendship match between units), and establish institutions.

\section{Conclusion}

To sum up, physical exercise is an important channel for human beings to strengthen physic quality. The help people maintain the consciousness of physical exercise is the important precondition for them to actively participate in physical exercise.

\section{Acknowledgement}

Project name: Current status of Ningxia Guyuan people-benefit project and standard system construction, Fund: Ningxia Philosophy and Social Science Planning Project (16NXBTY01).

\section{Reference}

[1] Shi Xianqiong. Analysis on factors influencing Henan migrant farmers' sport consciousness and behaviors, Contemporary Sports Technology, 2014, 4 (29):136-138.

[2] Chen Zhenhuai. Analysis on influence factors of rural public sports service demand level—take Chengdu as the example, Contemporary Sports Technology, 2016, 6(26):159-160.

[3] Xu Wei, Yao Lei, Lin Xinmao. Restraining factors of school sports reform and development-From base level investigation, Journal of Beijing Sport University, 2016, 39 (08):75-80.

[4] Sun Shijie, Sun Kang. Analysis on factors influencing college students' sports habit formation-take colleges in Shanghai as the example, Asia-Pacific Education, 2016, (18): 270.

[5] Chen Huawei, Ding Congong, Chen Jinwei. Measurement of nationwide fitness public sports resource allocation efficiency and analysis on influence factors, Journal of Xi'an Physical Education University, 2016, 33 (06):666-672.

[6] Chen Mingxiang. Current situation of Fujian high school students' physical fitness in 2014 and studies on influence factors, Fujian Sports Science and Technology, 2016, 35(05):62-64.

[7] Li Zheng, Dou Jianshu. Analysis on factors influencing middle school students' PE class study and countermeasure research, Contemporary Sports Technology,2016, 5 (33): 134-135. 